\title{
Identificação de áreas para implantação de usina de reciclagem de resíduos da construção e demolição com uso de análise multicritério
}

\author{
Identification of areas for the deployment of a \\ construction and demolition waste recycling plant using \\ multicriteria
}

\section{J osé Carlos Bohnenberger \\ J oão Francisco de Paula Pimenta \\ Marcos Vinicius Sanches Abreu \\ Ulisses Bifano Comini \\ Maria Lúcia Calijuri \\ Ana Paula de Moraes \\ Isaias da Silva Pereira}

J osé Carlos Bohnenberger Universidade Federal de Viçosa Viçosa - MG - Brasil

J oão Francisco de Paula Pimenta

Universidade Federal de Viçosa Viçosa - MG - Brasil

Marcos Vinicius Sanches Abreu Universidade Federal de Viçosa Viçosa - MG - Brasil

Ulisses Bifano Comini Universidade Federal de Viçosa Viçosa - MG - Brasil

Maria Lúcia Calijuri Universidade Federal de Viçosa Viçosa - MG - Brasil

Ana Paula de Moraes Instituto Federal de Minas Gerais Ouro Preto - MG - Brasil

Isaias da Silva Pereira Instituto Federal do Pará Itaituba - PA - Brasil

Recebido em 20/06/16 Aceito em 12/05/17

\section{Resumo}

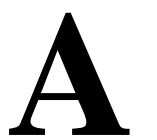

construção civil é responsável por um elevado consumo de recursos naturais e também pela geração de uma grande quantidade de resíduos de construção e de demolição (RCD). Uma alternativa para o gerenciamento sustentável dos RCDs é a reciclagem para uso na própria construção civil, o que permite a redução da demanda de recursos naturais e dos custos, além de amenizar o impacto gerado pela disposição inadequada desses resíduos no meio ambiente. Diante desse cenário, o presente trabalho tem como objetivo analisar e selecionar áreas para a implantação de uma usina de reciclagem de RCD no Município de Viçosa, MG. Foram utilizadas técnicas de sistemas de informações geográficas (SIG) que permitiram avaliar áreas alternativas por meio da aplicação da análise multicritério, tendo sido selecionadas 23 áreas possíveis para implementação da unidade. A análise complementar com visitação in loco permitiu a seleção de 4 áreas consideradas mais adequadas por apresentarem acesso facilitado, baixos valores imobiliários, ausência de edificações ou uso futuro predefinido. A metodologia adotada se mostrou apropriada para auxiliar na tomada de decisão e na diminuição do tempo necessário para a escolha de áreas destinadas à reciclagem de RCD, podendo ser replicada em outros municípios.

Palavras-chave: Resíduos de construção e demolição. Usina de reciclagem. Sistemas de informações geográficas. Análise multicritério. Gerenciamento de resíduos.

\section{Abstract}

The construction industry uses a high input of natural resources and generates a large amount of construction and demolition waste $(C D W)$. An alternative to the sustainable management of $C D W$ is the recycling of waste for use by the construction industry itself, thus reducing the demand on natural resources, the cost and the environmental impact caused by inadequate disposal. In this context, the aim of this study was to assess and select areas in which to implement a CDW recycling plant in Viçosa, MG, Brazil. Geographical Information Systems (GIS), especially Multi-Criteria Analysis, allowed the identification of 23 potential areas in which to implement the plant. On-site visits allowed the identification of 4 areas that are more adequate due to easy access, the absence of buildings, low market prices and no pre-defined future use. The methodology adopted has shown to be appropriate to assess and to reduce time in the decision-making process to define potential areas for $C D W$ recycling plants. It is also applicable in other municipalities.

Keywords: Construction and demolition waste. Recycling plant. Geographic information systems. Multi-criteria analysis. Waste management.

BOHNENBERGER, J. C.; PIMENTA, J. F. de P.; ABREU, M. V. S.; COMINI, U. B.; CALIJ URI, M. L.; MORAES, A. P. de; 


\section{Introdução}

A construção civil é causadora de grande impacto ambiental não somente pelo consumo de recursos naturais em toda a sua cadeia produtiva, como também pela disposição indiscriminada dos resíduos gerados na construção e demolição (RCD). Em termos globais, isso responde pelo uso de $40 \%$ das matérias-primas retiradas do meio ambiente, o que totaliza $60 \%$ de toda a madeira extraída, $40 \%$ de toda a energia produzida e $16 \%$ de toda a água potável (TRIGUEIRO, 2005). Mais de 26 bilhões de toneladas de concreto novo são utilizados anualmente em todo o mundo, conforme aponta Senaratne et al. (2016). O Panorama de Resíduos Sólidos da Associação Brasileira de Empresas de Limpeza Pública e Resíduos Especiais (Abrelpe) apresenta dados de RCD coletados em todo o país, no montante de 45 milhões de toneladas por ano (ASSOCIAÇÃO BRASILEIRA DE EMPRESAS..., 2015), porém não há definição das unidades de referência para análise de um coeficiente de geração nem do montante gerado. Mesmo com o Plano Nacional de Resíduos Sólidos, em sua versão preliminar até hoje não consolidada pelo Ministério do Meio Ambiente (MMA), não há apresentação de dados da geração total de RCD no país (MINISTÉRIO..., 2011).

A Resolução no 307/2002 do Conselho Nacional de Meio Ambiente (Conama) estabelece diretrizes, critérios e procedimentos para o gerenciamento dos resíduos da construção civil (CONSELHO..., 2002). Entre os aspectos relevantes, a norma trata da reciclagem dos RCDs, principalmente dos agregados, alvo de diversos estudos (RAO; JHA; MISRA, 2007; CASUCCIO et al., 2008; MIRANDA; ANGULO; CARELI, 2009; RODRIGUES; FUCALE, 2014), como alternativa de viabilidade econômica, técnica e ambiental para mitigação dos impactos advindos dos elevados índices de consumo de matérias-primas e geração de resíduos.

Além dos aspectos referentes ao gerenciamento dos RCDs, a escolha de locais adequados para a implantação de usinas de reciclagem é uma tarefa complexa, visto que é necessário avaliar uma extensa faixa territorial a fim de identificar áreas que atendam aos requisitos técnicos, ambientais e econômicos, combinados com uma gama de critérios e informações que devem ser considerados nessa seleção.

O uso de técnicas de sistemas de informações geográficas (SIG) para a seleção dessas áreas, em especial aquelas que auxiliam a tomada de decisão com uma abordagem flexível na avaliação de diferentes critérios, permite a realização de avaliações complexas e precisas em vastas extensões territoriais, com sensível ganho de tempo e de qualidade no que diz respeito aos resultados.

Ross e Soland (1980) já visualizavam que os problemas práticos decorrentes da localização de serviços públicos envolviam uma abordagem multicritério, devendo ser modelados e tratados como tal. A utilização de análise multicritério, aliada a técnicas de geoprocessamento, é amplamente difundida para a escolha de áreas destinadas à implantação de aterros sanitários como destinação final de resíduos sólidos urbanos (CALIJURI et al., 2007; CASTRO et al., 2015), contudo ainda é pouco difundida na identificação de áreas destinadas à reciclagem de RCD (BANIAS et al., 2010). Aldana e Serpell (2012) e Deus, Basttistelle e Silva (2015) não identificaram outros trabalhos que envolvessem SIG e análise multicritério na seleção de áreas para usinas de reciclagem de RCD.

No Município de Viçosa, MG, com o aquecimento econômico das últimas décadas no setor da construção civil, a geração de RCD passou a ser um grave problema ambiental. Até o ano de 2006 a inexistência de legislação específica para controle desses resíduos dificultou as ações do poder público. A partir daquele ano o Conselho Municipal de Defesa e Conservação do Meio Ambiente (Codema) publicou a Deliberação Normativa $n^{\circ} 06 / 2006$, que passou a exigir o descarte de RCDs nos bota-foras licenciados, que são aterros destinados exclusivamente aos RCDs, e o licenciamento de obras com movimentação de terra acima de $1.000 \mathrm{~m}^{3}$, modificação em área igual ou maior que $2.000 \mathrm{~m}^{2}$ ou, ainda, que se localizarem em áreas de proteção, preservação ou consideradas de risco ambiental (CONSELHO MUNICIPAL..., 2006).

Desde então, embora se tenha avançado com a diminuição da utilização de áreas irregulares, ainda não há formas sustentáveis de destinação, pois os bota-foras não dão uso aos resíduos recebidos. Segundo dados apresentados pelo Instituto de Planejamento do Município de Viçosa (IPLAM), atualmente a capacidade licenciada dos bota-foras no município é de $60.410 \mathrm{~m}^{3}$, distribuídos em seis áreas distintas, tendo sido outras dez já encerradas, totalizando um volume de $226.000 \mathrm{~m}^{3}$ (INSTITUTO DE PLANEJAMENTO..., 2016).

Este trabalho tem como objetivo analisar e selecionar áreas para a implantação de uma usina de reciclagem de RCD no Município de Viçosa, MG, utilizando-se técnicas de SIG que permitem 
avaliar áreas alternativas com a aplicação da análise multicritério.

\section{Reciclagem dos resíduos sólidos de construção e demolição}

A reciclagem e o reaproveitamento de RCD podem contribuir para o desenvolvimento sustentável à medida que minimizam a geração de resíduos descartados e o consumo de matéria-prima não renovável; assim, são reduzidos os impactos ambientais advindos das atividades de extração de matéria-prima e disposição final dos resíduos. Sabe-se que a indústria da construção civil é capaz de absorver quase totalmente os resíduos por ela gerados, com a possibilidade de incorporar novos materiais de construção originados da reciclagem e do reaproveitamento dos RCDs. Como exemplo ressalta-se a possibilidade de produzir agregados, areia, brita, blocos, tubos para drenagem, placas e componentes construtivos para uso em pavimentação, contenção de encostas, canalização de córregos, uso em argamassas e concreto. As usinas de reciclagem de RCD têm se mostrado viáveis técnica e economicamente (COELHO; BRITO, 2013), reduzindo custos e energia ao longo da cadeia produtiva do setor da construção civil (DAHLBO et al., 2015), além de ser uma alternativa para a geração de emprego e renda, tanto na coleta quanto nas usinas de reciclagem. Cabe salientar a importância da segregação dos resíduos na fonte geradora, por permitir a otimização do processo de reciclagem e influenciar diretamente na qualidade dos produtos (DAHLBO et al., 2015).

A União Europeia definiu como meta global para o continente a reciclagem de $70 \%$ de seus RCDs até 2020 (UNIÃO EUROPÉIA, 2008). Embora a taxa atual seja da ordem de $46 \%$, ainda distante da meta, alguns países, como Holanda, Dinamarca e Alemanha, detêm percentuais acima de 75\%, enquanto outros, como Portugal, Grécia e Espanha, possuem menos de 15\% de seus RCDs destinados à reciclagem (RODRIGUEZ et al., 2015). Na Alemanha, em 2007, havia aproximadamente 4.600 usinas de reciclagem de RCD, sendo 3.000 usinas móveis e 1.600 fixas. No entanto, mesmo com um alto índice de reciclagem, menos de $20 \%$ do agregado natural acaba realmente sendo substituído pelo agregado reciclado (MUELLER, 2007).

Na Espanha, segundo Rodriguez et al. (2015), o modelo de gestão das usinas de reciclagem de RCD é em geral de administração privada, com um raio de influência de $30 \mathrm{~km}$ de distância. Porém, a sustentabilidade dessas atividades apresenta desafios quanto à falta de controle dos aterros ilegais, diferenças significativas de tarifas para destinação dos RCDs e ausência de legislação regulamentando o uso de agregados reciclados. Os citados autores indicam uma revisão do modelo de gestão com reforço do papel do governo, aplicando a legislação ambiental, priorizando suas metas de reciclagem (70\%) e promovendo a utilização de agregados reciclados, atualmente da ordem de $14 \%$.

Inicialmente, no Brasil, foram instaladas usinas de reciclagem de RCD nos Municípios de São Paulo, em 1991, Londrina, em 1993, e Belo Horizonte, em 1994 (PINTO, 1999), porém somente a partir de 2000 é que começaram a ser desenvolvidas pesquisas sistemáticas para o uso de RCD como agregados. Até 2002 o país contava com 16 usinas de reciclagem de RCD, número esse ampliado para 47 após a publicação da Resolução $n^{\circ} 307$ do Conama, das quais 24 eram públicas e 23 de gestão privada (MIRANDA; ANGULO; CARELI, 2009). Já em 2015 dados apresentados pela Associação Brasileira para Reciclagem de Resíduos da Construção Civil e Demolição (Abrecon) apontaram para pelo menos 310 usinas de reciclagem de RCD espalhadas pelo país, sendo $83 \%$ privadas, $7 \%$ parcerias público-privadas e 10\% públicas (ASSOCIAÇÃO BRASILEIRA PARA RECICLAGEM..., 2015)

De acordo com a NBR 15114 (ABNT, 2004), a usina de reciclagem de RCD é um espaço físico constituído de equipamentos necessários para reciclagem dos resíduos sólidos de construção classe A, subdividido em pátios para estocagem, recebimento, manuseio e armazenamento dos materiais produzidos, de acessos para manobras de veículos e de área para administração. Sua instalação e sua operação requerem planejamento, infraestrutura administrativa e urbana, equipamentos, locais de apoio para organização e triagem do entulho, e a estação de reciclagem propriamente dita.

Embora existam normas técnicas que orientem a utilização do agregado reciclado para determinados usos, a Política Nacional de Resíduos Sólidos (BRASIL, 2010) e outras resoluções estaduais e municipais relacionadas ao gerenciamento de RCD, observa-se que a ausência de metas preestabelecidas em âmbito nacional dificulta a ampliação de práticas de reciclagem desse resíduo, diferentemente do que se vê em diversos países da União Europeia. 


\section{Critérios para a localização de usina de reciclagem de RCD}

Vários aspectos devem ser considerados ao se definir a localização de uma usina de reciclagem de RCD e durante o processo de operação em relação ao impacto visual e ambiental, levando em consideração a emissão de poeira, a segurança, a proteção dos operários e o nível de ruídos. Além dos fatores enunciados, essa localização deve atender:

(a) à regulamentação do uso do solo no município;

(b) à identificação das regiões geradoras dos maiores volumes de resíduos; e

(c) à existência de eixos viários para facilitar o deslocamento de veículos de maior porte.

A NBR 15114 (ABNT, 2004) estabelece que o local destinado à implantação de área de reciclagem de RCD deve prever a minimização dos impactos ambientais, a maximização do consentimento da população e o respeito às legislações de uso do solo e ambiental vigentes, ressaltando ainda a observância da hidrologia, vegetação e vias de acesso para avaliação da adequabilidade de possíveis locais para sua implantação.

A importância na escolha de um local adequado para instalação de uma usina de reciclagem de RCD fica evidente no caso de Itatinga, SP. Tal usina, inaugurada em 1991, passou uma temporada desativada e ainda permanecia ociosa em 2007, por estar longe dos centros geradores (COUTO NETO, 2007). Corbioli (1996) salienta que a unidade, projetada para reciclar 1.000 t/dia, operava em 1996 com apenas 50\% de sua capacidade devido à locação mal planejada, ficando muito distante daqueles que deveriam entregar seus resíduos no local.

Em estudo de identificação da localização de aterros sanitários, Samizava et al. (2005) afirmam que, para a realização das análises na escolha da área, os custos econômicos e de tempo são altos, pois vários são os parâmetros e informações levados em consideração. Jadovski (2005), a partir da análise de 7 unidades instaladas em municípios brasileiros, recomendou relações entre capacidade produtiva e área requerida para instalação de usina de reciclagem de RCD: $10 \mathrm{t} / \mathrm{h}\left(5.000 \mathrm{~m}^{2}\right), 20 \mathrm{t} / \mathrm{h}$ $\left(6.500 \mathrm{~m}^{2}\right), 40 \mathrm{t} / \mathrm{h}\left(10.000 \mathrm{~m}^{2}\right)$ e $100 \mathrm{t} / \mathrm{h}(20.000$ $\left.\mathrm{m}^{2}\right)$.

\section{Análise Multicritério}

Os SIGs são há muito tempo utilizados como ferramentas de apoio à decisão, por manipular grandes volumes de dados, integrar imagens orbitais e possuir potencial para realizar uma diversidade de análises com eficiência em curto espaço de tempo e a custos baixos (CALIJURI et al., 2007).

As aplicações de métodos multicritério ganham cada vez mais aceitação no que diz respeito aos modelos quantitativos, pois conseguem incorporar em sua análise muitas variáveis, sejam elas qualitativas ou quantitativas. É possível simular e avaliar vários cenários simultaneamente, buscando uma solução otimizada. Essa análise consiste em modelar espacialmente os diferentes critérios, que determinam a escolha de uma área apropriada para dada finalidade (CASTRO et al., 2015). Trabalhase nesse contexto com os conceitos de restrição e de adequabilidade.

De acordo com Santos et al. (2012), as restrições tratam de critérios relacionados às questões legais associadas à impossibilidade de alteração do ambiente em determinadas localizações, tais como proximidade de cursos d'água, de áreas de proteção ambiental (APAs), de áreas de preservação permanente (APPs) e de parques, ou, ainda, proximidade de áreas densamente ocupadas. Por sua vez, o conceito de adequabilidade se refere à adoção de uma escala de valores para representar o quão mais adequada é uma área em relação às outras. Essa escala de valores de adequabilidade é padronizada, geralmente se adotando valores entre 0 e 255, conforme a aptidão de um critério, onde 0 representa menor aptidão, e 255, maior aptidão (SANTOS et al., 2012). Neste trabalho adotou-se o termo "fator" àqueles critérios de aptidão padronizados na escala de 0 a 255.

Os fatores poderão ser representados por variáveis discretas ou variáveis contínuas. Nos fatores representados pelas variáveis discretas, como tipo de solo ou uso e ocupação do solo, cada classe é associada a um valor numérico, indicando, assim, seu grau de adequabilidade à análise proposta. Já os fatores representados por variáveis contínuas, como distâncias e declividades, têm seus valores reescalonados, de forma crescente ou decrescente, segundo sua aptidão, utilizando-se as funções de modelagem fuzzy, que regem a variação entre os valores que afetam a adequabilidade de um critério (SANTOS et al., 2012).

Após a padronização dos valores dos fatores, escalonados entre 0 e 255 , é realizado o processo de agregação, valendo-se da adoção de pesos para cada fator, que indicam sua importância 
hierárquica no processo de tomada de decisão. O processo de agregação pode ser de dois tipos: a Combinação Linear Ponderada (Weighted Linear Combination - WLC) e a Média Ponderada Ordenada (Ordered Weighted Average - OWA) (LORENTZ et al., 2016).

A adoção dos pesos é arbitrária e depende da avaliação do analista. Uma forma de reduzir a arbitrariedade e eventuais inconsistências na obtenção dos pesos para cada fator é a utilização da técnica chamada Processo Hierárquico Analítico (Analytical Hierarchical Process AHP). Tal técnica consiste em uma comparação de importância par a par em que todos os fatores são ordenados de forma implícita pelo analista. O processo de desenvolvimento dos pesos avalia a consistência da comparação, indicando se foi aleatória ou não. Por fim, os pesos de cada fator são gerados em um intervalo fixado entre 0 e 1 (CASTRO et al., 2015; LORENTZ et al., 2016).

Após a agregação dos diferentes critérios (restrições e fatores), já padronizados e hierarquizados, um fator com baixa adequabilidade pode ser compensado por outro que apresente valor mais alto. O nível de compensação pode ser definido pelo analista através da Média Ponderada Ordenada (OWA), que consiste na definição de um segundo conjunto de pesos, que, combinados novamente, controlam o quanto um fator de alta adequabilidade compensa outro de baixa adequabilidade em dada região (EASTMAN et al., 1995). Esse grau de compensação está associado ao risco de se assumir um cenário para a tomada de decisão, enquanto esse risco diz respeito ao fato de valores baixos serem compensados pela presença de valores altos, e valores altos compensados pelos baixos.

A Figura 1 ilustra o modelo de risco-compensação. Ressalta-se que o menor risco tem o valor igual a 1 , e o maior risco, igual a 0 . Já a compensação é menor quando se aproxima de 0 e maior quando se aproxima de 1 .

Ao final desse processo de padronização, hierarquização, agregação e compensação dos diversos critérios, são gerados diferentes cenários de risco versus compensação, que são apresentados na forma de superfícies coloridas, representando escala contínua de valores entre 0 e 255, que indicam o grau de adequabilidade das áreas encontradas, como demonstrado mais adiante neste trabalho, nas Figuras 2 e 3.
Cabe ainda destacar que não existem técnicas de análises multicritério melhores ou piores, e sim aquelas mais ou menos adequadas ao problema em estudo (BANIAS et al., 2010).

\section{Método \\ Materiais}

Embora existam diversas opções de softwares para desenvolvimento das análises realizadas neste trabalho, os programas adotados foram selecionados pela qualidade em seus resultados, pela facilidade de acesso a sistemas devidamente licenciados e pela experiência dos autores em utilizá-los, os quais são:

(a) IDRISI Selva ${ }^{\circledR}$, para a classificação do uso e ocupação do solo do município, bem como para a modelagem dos fatores, através da lógica fuzzy e a análise multicritério;

(b) ArcGIS $10.3 .1^{\circledR}$, para a geração dos mapas finais; e

(c) Google Earth Pro ${ }^{\circledR}$, para a identificação da paisagem das áreas selecionadas.

Os dados de entrada utilizados foram:

(a) imagem LandSAT $8^{\circledR}$, de julho de 2015;

(b) mapa de solos do município, cedido pelo laboratório de SIG do DEC-UFV;

(c) mapas de vias e praças cedidos pelo Projeto Viçosa Digital e por Silva (2012);

(d) mapas de hidrografia e relevo, obtidos no mapeamento sistemático do Instituto Brasileiro de Geografia e Estatística (IBGE); e

(e) mapa de equipamentos urbanos, gerado pelos autores.

\section{Área de estudo}

O Município de Viçosa, localizado na região da Zona da Mata de Minas Gerais, possui área de 300 $\mathrm{km}^{2}$, com população de 77.318 habitantes, segundo dados do IBGE (INSTITUTO BRASILEIRO..., 2016). Cerca de $98 \%$ da população é atendida por sistemas de abastecimento de água, e $88 \%$ com sistemas de coleta de esgoto. Diariamente são coletadas 50 toneladas de resíduos sólidos urbanos, dos quais $80 \%$ são destinados ao aterro sanitário e $20 \%$ à usina de triagem, conforme dados do Saae (SERVIÇO..., 2016). 
Figura 1 - Modelo de risco-compensação para análise multicritério para definição de cenários

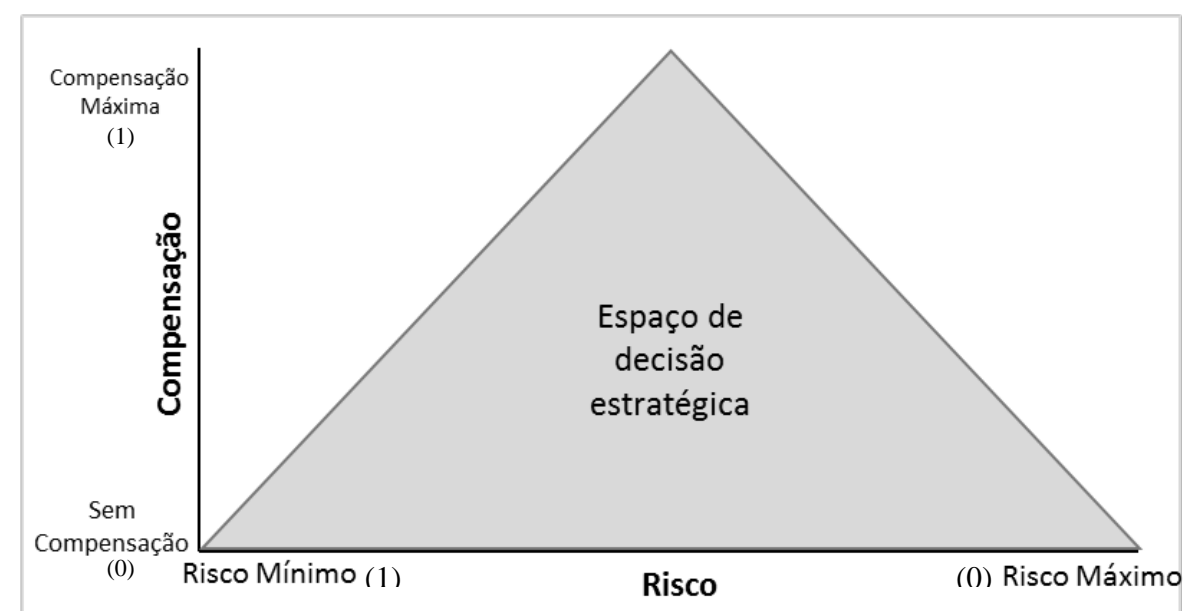

Fonte: adaptado de Eastman (2006).

Em Viçosa, MG, de acordo com dados do Iplam (INSTITUTO DE PLANEJAMENTO..., 2016), foram emitidos alvarás de construção para edificações nos anos de 2013, 2014 e 2015, que totalizaram áreas construídas de $380.000 \mathrm{~m}^{2}$, $311.000 \mathrm{~m}^{2}$ e $342.000 \mathrm{~m}^{2}$ respectivamente. Considerando o coeficiente de geração médio indicado por Sáez et al. (2014), de 117,50 kg de $\mathrm{RCD} / \mathrm{m}^{2}$ construído, chega-se a valores da ordem de 45.000 toneladas de RCD, como estimativa de geração anual para Viçosa, sendo 2013 o ano de maior geração da série. Esse valor demanda uma usina de reciclagem de RCD com capacidade de processamento da ordem de $22 \mathrm{t} / \mathrm{h}$.

Para fins deste trabalho, considerando a elevação da atividade da indústria da construção civil, o fator de segurança relacionado a possíveis expansões e a possibilidade do processamento dos resíduos gerados nos municípios circunvizinhos, optou-se por uma usina com capacidade de processamento de $40 \mathrm{t} / \mathrm{h}$, que necessita de uma área de 1 ha para sua implementação, de acordo com Jadovski (2005).

\section{Fatores e restrições adotados na seleção das áreas}

Foram adotados fatores e restrições para a seleção de áreas para a construção da usina de reciclagem de RCD. As restrições são critérios que impossibilitam a utilização de áreas para implantação do empreendimento. Já os fatores são todas as limitações que definem o grau de adequabilidade aos espaços disponíveis, classificando-os em mais ou menos aptos para determinado uso (LORENTZ et al., 2016).

Como restrições figuram a declividade máxima de $30 \%$, a fim de diminuir os custos com terraplenagem, a distância mínima de $30 \mathrm{~m}$ da hidrografia, de acordo com o código florestal, a distância mínima de $30 \mathrm{~m}$ do sistema viário, de modo a garantir uma proteção visual e acústica da usina, e a exclusão das áreas com vegetação natural e de ocupação urbana.

Os fatores foram padronizados em uma escala crescente de adequabilidade variando de 0 a 255 , em uma escala contínua através das funções da lógica fuzzy (algoritmo), ou em classes definidas pelos autores quando se tratava de dados categóricos.

A valoração entre os fatores foi feita por meio do AHP, que compara a importância relativa dos fatores aos pares; e, após a determinação de todas as combinações possíveis, calculam-se um primeiro conjunto de pesos e a razão de consistência das ponderações realizadas. A Tabela 1 elenca os critérios, as restrições, as funções e os respectivos fatores com seus pontos de controle, bem como os pesos obtidos para cada fator. Esses fatores foram agregados pela OWA, em que se aplicou um segundo conjunto de pesos para o controle do risco e da compensação, gerando diferentes cenários.

A Tabela 2 apresenta os quatro cenários analisados, com seus respectivos riscos e compensações. Ao final da realização da OWA foram escolhidas as áreas privadas e não edificadas com mais de 1 ha.

\section{Resultados e discussão}

A Figura 2 apresenta as superfícies de adequabilidade para a construção da usina de reciclagem de RCD. O primeiro cenário (1) teve risco médio $(0,50)$ e compensação máxima $(1,00)$, 
Figura 2 - Cenários analisados com indicação da escala de adequabilidade

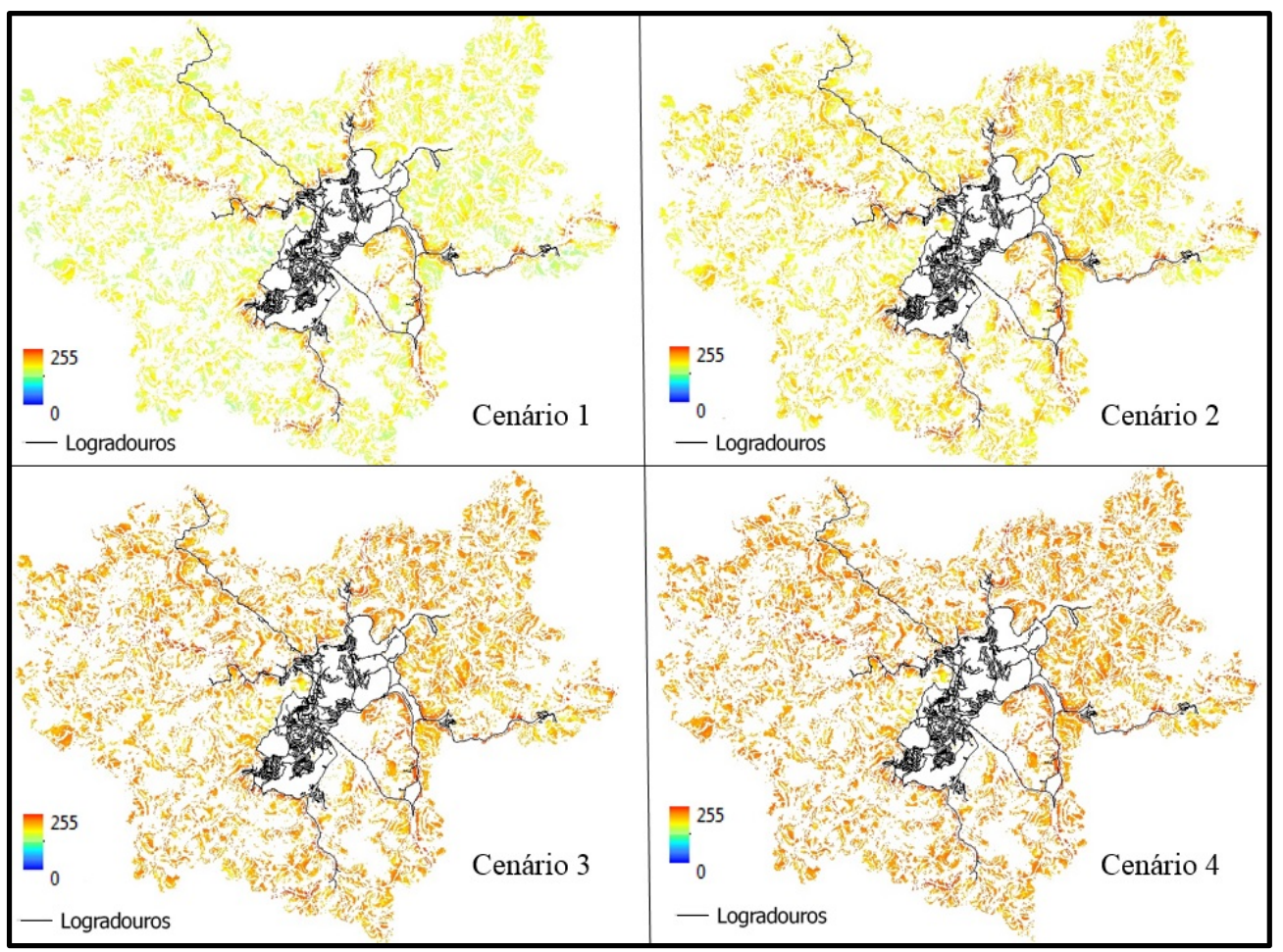

Figura 3 - Áreas maiores que 1 ha que atendem aos critérios com adequabilidade superior a 230 para os diferentes cenários analisados

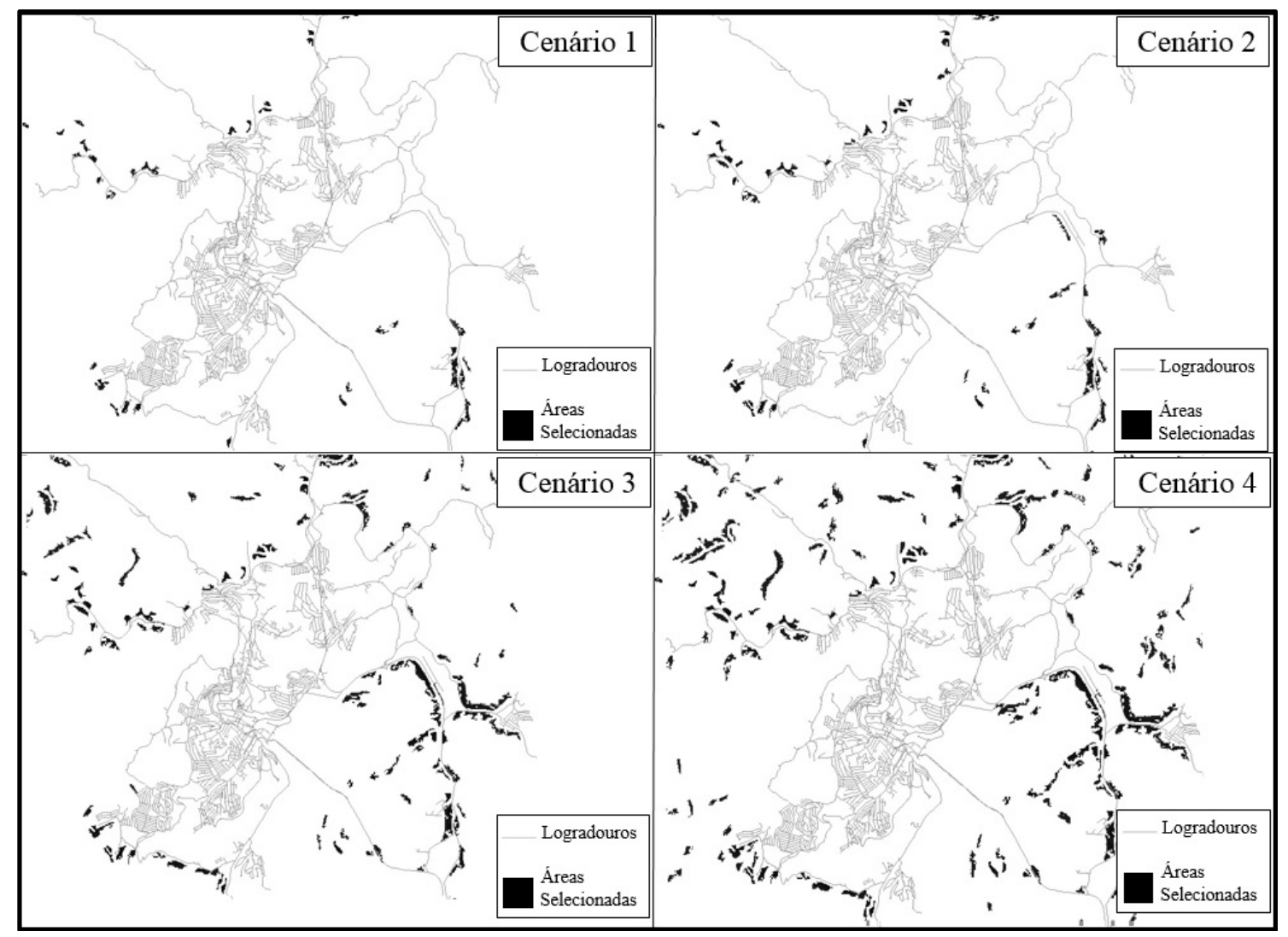

306 Bohnenberger, J. C.; Pimenta, J . F. de P.; Abreu, M. V. S.; Comini, U. B.; Calijuri, M. L.; Moraes, A. P. de; Pereira, I. da S. 
A Figura 4 mostra as 23 áreas selecionadas, identificadas por um código numérico de 1 a 23, bem como a localização da ETA I, da ETA II, da ETE da Barrinha e do Aterro Sanitário.

\section{Validação dos resultados e visitas in loco}

Foram realizadas visitas in loco que permitiram validar a metodologia proposta. Todas as áreas foram consideradas aptas para a implantação da usina, respeitando as restrições estabelecidas.

Entretanto, foi possível identificar diferentes graus de aptidão em função de aspectos positivos e negativos, tais como facilidade de deslocamento pelas vias existentes, acessibilidade para veículos motorizados e de tração animal, proximidade das fontes geradoras de resíduos e do aterro sanitário, formato inadequado da área, necessidade de construir pontes ou vias de acesso, uso e ocupação da área com construções rurais e expansão urbana com valorização imobiliária. A Tabela 3 apresenta um resumo decorrente dessa avaliação.

Parte dos aspectos negativos está relacionada às limitações do banco de dados utilizado, especialmente no que diz respeito à ocupação da zona rural, construções recentes ou ainda não cadastradas e áreas localizadas na margem oposta do curso d'água.

A Tabela 4 mostra as características das 4 melhores áreas identificadas para a implantação da usina de reciclagem de RCD e suas distâncias em relação aos critérios de análise fixados na Tabela 1. Essas áreas margeiam uma rodovia federal, considerada via preferencial, respeitando o afastamento mínimo estabelecido para as vias e a hidrografia. Embora o aterro sanitário municipal não tenha sido objeto de análise, sua distância em relação a cada área escolhida foi determinada, pois facilita o descarte dos rejeitos da usina.

\section{Conclusões e recomendações}

O uso da análise multicritério constituiu-se em uma ferramenta eficiente tanto no aspecto de economia de tempo quanto na possibilidade de análise conjunta de uma ampla gama de critérios no processo de seleção das áreas para a usina de reciclagem de RCD.

A análise multicritério apresentou como resultado 23 áreas que atenderam a todos os critérios (restrições e fatores) estabelecidos para a localização da usina de reciclagem de RCD no Município de Viçosa, MG.

Figura 4 - Áreas selecionadas para a usina de reciclagem de RCD

Mapa de áreas selecionadas para a construcão da Usina RCD

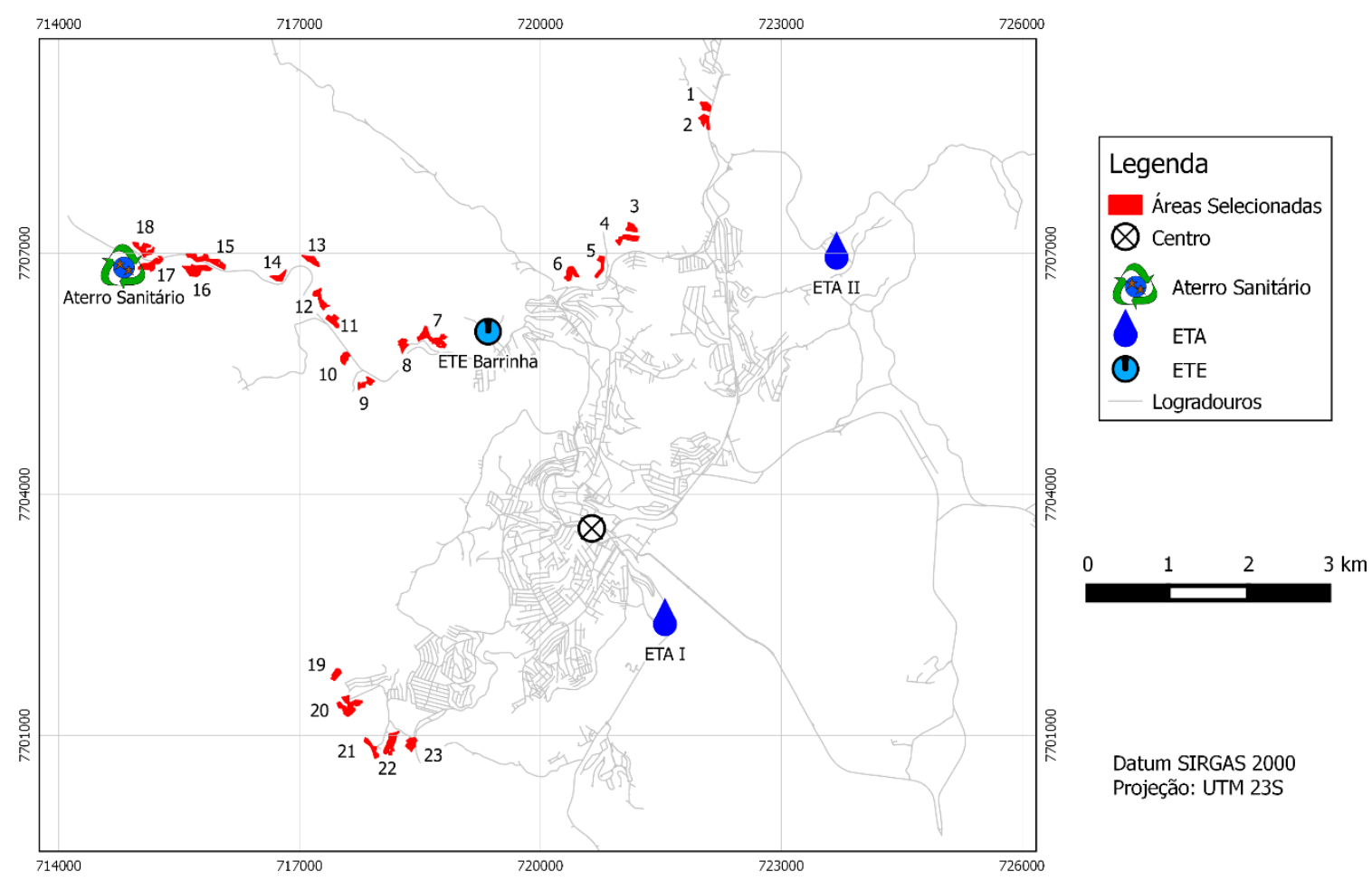


Tabela 3 - Caracterização das áreas selecionadas pela análise multicritério

\begin{tabular}{|c|c|c|}
\hline Áreas & Aspectos negativos & Tamanho (ha) \\
\hline $\begin{array}{l}1 \text { e } 2 \\
3 \\
4,5,6 \text { e } 7 \\
8,9 \text { e } 10 \\
11 \\
12,13 \text { e } 14 \\
15 \\
16,17 \text { e } 18 \\
19,20,21,22 \text { e } 23\end{array}$ & $\begin{array}{l}\text { Alta valorização imobiliária } \\
\text { Necessita de ponte para acesso } \\
\text { Área de expansão urbana } \\
\text { Presença de construções rurais } \\
\text { Não apresenta restrição } \\
\text { Necessita de ponte para acesso } \\
\text { Formato inadequado da área } \\
\text { Não apresentam restrições } \\
\text { Acesso difícil/longe do aterro }\end{array}$ & $\begin{array}{c}(1,03) /(1,26) \\
(1,00) \\
(1,50) /(1,29) /(1,56) /(2,95) \\
(1,02) /(1,03) /(1,02) \\
(1,67) \\
(1,51) /(1,14) /(1,04) \\
(2,72) \\
(2,80) /(2,12) /(1,93) \\
(1,00) /(3,14) /(1,24) /(2,39) /(1,00)\end{array}$ \\
\hline
\end{tabular}

Tabela 4 - Caracterização física das áreas indicadas para a implantação da usina de reciclagem de RCD

\begin{tabular}{l|c|c|c|c|c|c|c|c|c|c}
\hline \multirow{2}{*}{ Área } & \multirow{2}{*}{$\begin{array}{c}\text { Uso e } \\
\text { ocup. }\end{array}$} & Solos & $\begin{array}{c}\text { Centro } \\
\text { cidade }\end{array}$ & Aterro & \multicolumn{2}{|c|}{ Vias } & $\begin{array}{c}\text { Ocup. } \\
\text { densa }\end{array}$ & Praças & $\begin{array}{c}\text { Equip. } \\
\text { urb. }\end{array}$ & Hidr. \\
\hline 11 & Pastagem & $\begin{array}{c}\text { Argissolo vermelho } \\
\text { amarelo }\end{array}$ & 4.058 & 2.600 & 30 & 50 & 430 & 2.670 & 3.175 & 50 \\
16 & Pastagem & $\begin{array}{c}\text { Argissolo vermelho } \\
\text { amarelo }\end{array}$ & 5.840 & 750 & 30 & 30 & 1.190 & 4.362 & 4.956 & 30 \\
17 & Pastagem & $\begin{array}{c}\text { Argissolo vermelho } \\
\text { amarelo }\end{array}$ & 6.387 & 200 & 30 & 70 & 1.575 & 4.917 & 5.517 & 170 \\
\hline
\end{tabular}

A partir da vistoria in loco das 23 áreas selecionadas, foram escolhidas 4 que apresentaram as melhores características para a implantação de uma usina de reciclagem de RCD no município. É importante observar que as áreas se encontram bem próximas ao centro urbano municipal, o que facilita o acesso dos usuários.

Destaca-se que o estabelecimento dos critérios, a definição dos pontos de controle das funções fuzzy e a valoração dos fatores no processo AHP são as decisões mais complexas e subjetivas da análise multicritério, recomendando-se que sejam realizadas por meio de uma equipe multidisciplinar que compreenda as especificidades locais.

Sugere-se para o caso específico do Município de Viçosa a implantação de um plano integrado de gerenciamento de RCD por parte dos gestores municipais que considere o volume gerado de RCD, sua composição, os meios de transporte e os responsáveis pela produção, com ênfase na reciclagem e uso final.

Estudos socioeconômicos devem ser realizados para a seleção definitiva da área de implantação da usina de reciclagem de RCD. Ressalta-se que este trabalho não realizou tais estudos, apesar de considerá-los indispensáveis para o sucesso econômico do empreendimento.
A metodologia utilizada no presente trabalho pode ser replicada em outros municípios que têm interesse de implantar uma usina de reciclagem de RCD. No entanto, a eficiência da metodologia dependerá da atualização e da qualidade do banco de dados para as análises no SIG, nem sempre disponível nos municípios brasileiros, exigindo-se levantamento prévio de dados e cautela na avaliação dos resultados.

\section{Referências}

ALDANA, J.; SERPELL, A. Temas y Tendencias Sobre Residuos de Construcción y Demolición: un Meta-Análisis. Revista de la Construcción, v. 12, n. 22, p. 4-16, 2012.

\section{ASSOCIAÇÃO BRASILEIRA DE EMPRESAS \\ DE LIMPEZA PÚBLICA E RESÍDUOS}

ESPECIAIS. Panorama dos Resíduos Sólidos no

Brasil 2014. São Paulo, 2015. Disponível em:

$<$ http://www.abrelpe.org.br/panorama_apresentaca o.cfm>. Acesso em: 10 jun. 2016.

\section{ASSOCIAÇÃO BRASILEIRA DE NORMAS} TÉCNICAS. NBR 15114: resíduos sólidos da construção civil: áreas de reciclagem: diretrizes para projeto, implantação e operação. Rio de Janeiro, 2004. 
ASSOCIAÇÃO BRASILEIRA PARA RECICLAGEM DE RESÍDUOS DA CONSTRUÇÃO CIVIL E DEMOLIÇÃO. Relatório Pesquisa Setorial 2014/2015: a reciclagem de resíduos de construção e demolição no Brasil. São Paulo, 2015. Disponível em: $<$ http://www.abrecon.org.br/relatorio-pesquisasetorial-20142015/>. Acesso em: 2 maio 2016.

BANIAS, G. et al. Assessing Multiple Criteria for the Optimal Location of a Construction and Demolition Waste Management Facility. Building and Environment, v. 45, p. 2317-2326, 2010.

BRASIL. Lei no 12.305 , de 2 de agosto de 2010: institui a Política Nacional de Resíduos Sólidos; altera a Lei no 9.605, de 12 de fevereiro de 1998; e dá outras providências. Diário Oficial da União, Brasília, DF, 3 de agosto de 2010.

CALIJURI, M. L. et al. Identificação de Áreas Alternativas Para Disposição de Resíduos Sólidos na Região do Baixo Ribeira do Iguape - SP.

Revista de Engenharia Sanitária e Ambiental, v. 12. n. 3, p. 247-251, 2007.

CASTRO, J. S. et al. Utilização de SIG e Análise Multicritério para seleção de áreas com potencial para a construção de universidades e loteamentos universitários. Boletim de Ciências Geodésicas. v. 21, n. 3, p. 652-657, jul./set. 2015.

CASUCCIO, M. et al. Failure Mechanism of Recycled Aggregate Concrete. Construction and Building Materials, v. 22, n. 7, p. 1500-1506, Jun. 2008.

COELHO, A.; BRITO, J. de. Economic Viability Analysis of a Construction and Demolition Waste Recycling Plant in Portugal - part I: location, materials, technology and economic analysis. Journal of Cleaner Production, v. 39, p. 338352, Jan. 2013.

CONAMA. CONSELHO NACIONAL DO MEIO AMBIENTE. Resolução 307, de 5 de julho de 2002. Dispõe sobre a gestão dos resíduos da construção civil. Diário Oficial da União, Poder Executivo, Seção 1, p. 95-96, Brasília, 17 de jul. 2002.

\section{CONSELHO MUNICIPAL DE DEFESA E} CONSERVAÇÃO DO MEIO AMBIENTE. Deliberação Normativa n ${ }^{\circ}$ 06/2006, de 4 de maio de 2006. Dispõe sobre normas específicas para licenciamento ambiental para a atividade de movimentação de terra e afins e dá outras providências. 2006.

CORBIOLI, N. Do Caos à Solução. Construção, São Paulo: Pini, v. 2505, p. 4-7, fev. 1996.

\section{COUTO NETO, A. G. Construção Civil}

Sustentável: avaliação da aplicação do modelo de Gerenciamento de Resíduos da Construção Civil do SINDUSCON-MG em um canteiro de obras: um estudo de caso. Belor Horizonte, 2007. $88 \mathrm{f}$. Dissertação (Mestrado em Engenharia Civil) Programa de Pós-Graduação em Meio Ambiente, Saneamento e Recursos Hídricos, Escola de Engenharia, Universidade Federal de Minas Gerais, Belo Horizonte, 2007.

DAHLBO, H. et al. Construction and Demolition Waste Management: a holistic evaluation of environmental performance. Journal of Cleaner Production, v. 107, p. 333-341, Nov. 2015.

DEUS, R. M.; BATTISTELLE, R. A. G.; SILVA, G. H. R. Resíduos Sólidos no Brasil: contexto, lacunas e tendências. Revista de Engenharia Sanitária e Ambiental, v. 20. n. 4, p. 685-698, out./dez. 2015.

EASTMAN, J. R. et al. Raster Procedures for Multicriteria/Multi-Objective Decisions.

Photogrammetry Engineering \& Remote Sensing, v. 61, n. 5, p. 539-547, 1995.

EASTMAN, J. R. TerrSet Manual: geospatial monitoring and modeling system. Worcester: Clark LabsClark University, 2006.

INSTITUTO BRASILEIRO DE GEOGRAFIA E ESTATÍSTICA. Ministério do Planejamento, Orçamento e Gestão. IBGE-cidades@. 2016. Disponível em:

$<$ http://cidades.ibge.gov.br/xtras/perfil.php?codmu $\mathrm{n}=317130>$. Acesso em: 3 jun. 2016.

INSTITUTO DE PLANEJAMENTO DO MUNICÍPIO DE VIÇOSA. Livros de Alvarás dos Anos de 2013 a 2015. Viçosa, 2016. Consulta pessoal ao acervo do Iplam.

JADOVSKI, I. Diretrizes Técnicas e Econômicas Para Usinas de Reciclagem de Resíduos de Construção e Demolição. Porto Alegre, 2005. 178 f. Trabalho de conclusão (Mestrado Profissional em Engenharia) - Programa de Mestrado Profissionalizante em Engenharia, Universidade Federal do Rio Grande do Sul, Porto Alegre, 2005.

LORENTZ, J. F. et al. Multicriteria Analysis Applied to Landslide Susceptibility Mapping. Natural Hazards, v. 1, p. 12-27, 2016.

MINISTÉRIO DO MEIO AMBIENTE. Plano Nacional de Resíduos Sólidos. Versão Preliminar. Brasília, 2011. Disponível em:

<http://www.mma.gov.br/estruturas/253/_publicac ao/253_publicacao02022012041757.pdf $>$. Acesso em: 10 jun. 2016. 
MIRANDA, L. F. R.; ANGULO, S. C.; CARELI, E. D. A Reciclagem de Resíduos de Construção e Demolição no Brasil: 1986-2008. Ambiente Construído, Porto Alegre, v. 9, n. 1, p. 57-71, jan./mar. 2009.

MUELLER, A. Closed Loop of Concrete Rubble? Bauhaus Universitat Weimar [notas de aula]. 2007. Disponível em:

$<$ www.uniweimar.de/Bauing/aufber/Lehre/Gastvor lesung/Barcelona/Lecture07.pdf>. Acesso em: 5 jul. 2009.

PINTO, T. P. Metodologia Para a Gestão Diferenciada de Resíduos Sólidos da Construção Urbana. São Paulo, 1999. 189 f. Tese (Doutorado em Engenharia) - Escola Politécnica, Universidade de São Paulo, São Paulo, 1999.

RAO, A.; JHA, K. N.; MISRA, S. Use of Aggregates From Recycled Construction and Demolition Waste in Concrete. Resources, Conservation and Recycling, v. 50, n. 1, p. 7181, Mar. 2007.

RODRIGUES, C. R. S.; FUCALE, S. Dosagem de Concretos Produzidos Com Agregado Miúdo Reciclado de Resíduo da Construção Civil.

Ambiente Construído, Porto Alegre, v. 14, n. 1, p. 99-111, jan./mar. 2014.

RODRÍGUEZ, G. et al. Assessment of Construction and Demolition Waste Plant Management in Spain: in pursuit of sustainability and eco-efficiency. Journal of Cleaner Production, v. 90, p. 16-24, Mar. 2015.

ROSS, T.; SOLAND, R. A Multicriteria Approach to the Location of Public Facilities. European Journal of Operational Research, v. 4, n. 5, p. 307-321, 1980.

SÁEZ, P. V. et al. Assessing the Accumulation of Construction Waste Generation During Residential Building Construction Works. Resources,

Conservation and Recycling, v. 93, p. 67-74, 2014.
SAMIZAVA, T. M. et al. SIG Aplicado à Avaliação de Áreas Para Instalação de Aterro Sanitário no Município de Presidente Prudente SP. In: CONGRESSO BRASILEIRO DE ENGENHARIA SANITÁRIA E AMBIENTAL, 23., Campo Grande, 2005. Anais... Campo Grande, 2005.

SANTOS, A. P. et al. O Uso da Análise Multicritério no Mapeamento da Fragilidade Social da Área Urbanizada do Município de Viçosa - MG. Revista Brasileira de Cartografia, v. 64/5, p. 635-643, 2012.

SENARATNE, S. et al. The Costs and Benefits of Combining Recycled Aggregate With Steel Fibres as a Sustainable, Structural Material. Journal of Cleaner Production, v. 112, n. 4, p. 2318-2327, Jan. 2016.

\section{SERVIÇO AUTÔNOMO DE ÁGUAS E}

ESGOTOS. [Site institucional]. Disponível no site: $<$ http://www.saaevicosa.com.br>. Acesso em: 31 maio 2016.

SILVA, A. J. P. A. Proposta de Mobilidade Urbana e Ocupação Territorial Utilizando Análise Multicritério: estudo de caso aplicado ao Município de Viçosa e área de influência. Voçosa, 2012. 177 f. Tese (Doutorado em Engenharia Civil) - Departamento de Engenharia Civil, Universidade Federal de Viçosa, Viçosa, 2012.

TRIGUEIRO, A. Mundo Sustentável: abrindo espaço na mídia para um planeta em transformação. São Paulo: Globo, 2005.

UNIÃO EUROPEIA. Diretiva 2008/98/CE do Parlamento Europeu e do Conselho de 19 de novembro de 2008 relativa aos resíduos e que revoga certas diretivas. 2008. 


\section{J osé Carlos Bohnenberger}

Departamento de Engenharia Civil, Centro de Ciências Exatas e Tecnológicas | Universidade Federal de Viçosa | Avenida da Agronomia, s/n, Prédio do CCE, Campus | Viçosa - MG - Brasil | CEP 36570-000 | Tel.: (31) 3899-1740 | E-mail: bohnen@ufv.br

\section{J oão Francisco de Paula Pimenta}

Divisão de Água e Esgoto | Universidade Federal de Viçosa | Avenida Peter Henry Rolfs, s/ n, Campus Universitário | Viçosa - MG - Brasil | CEP 36570-000 | Tel.: (31) 3899-2826 | E-mail: joao.pimenta@ufv.br

\section{Marcos Vinicius Sanches Abreu}

Departamento de Engenharia Civil, Centro de Ciências Exatas e Tecnológicas | Universidade Federal de Viçosa | Avenida da Agronomia, s/n, Prédio do CCE, Campus | Viçosa - MG - Brasil | CEP 36570-000 | Tel.: (31) 3899-3035 | E-mail: msanchesabreu@yahoo.com.br

\section{Ulisses Bifano Comini}

Divisão de Gerenciamento de Resíduos | Universidade Federal de Viçosa | Av. Peter Hemry Rolfs, s/n, Centro | Viçosa - MG - Brasil | CEP 36570-000 | Tel.: (31) 3899-2558 | E-mail: ulisses.comini@ufv.br

\section{Maria Lúcia Calijuri}

Departamento de Engenharia Civil, Centro de Ciências Exatas e Tecnológicas | Universidade Federal de Viçosa | Tel.: (31) 3899-3093 | E-mail: calijuri@ufv.br

\section{Ana Paula de Moraes}

Curso de Tecnologia em Conservação e Restauro | Instituto Federal de Minas Gerais | Rua Pandiá Calógeras, 898, Campus Ouro Preto, Bauxita | Ouro Preto - MG - Brasil | CEP 35400-000 | Tel.: (31) 3559- 2100 | Email: anapaula.moraes@ifmg.edu.br

\section{Isaias da Silva Pereira}

Coordenação de Agroecologia | Intituto Federal do Pará | Estrada do J acarezinho, Km 5, s/ n, Campus Itaituba, Maria Madalena | Itaituba - PA - Brasil | CEP 68180-000 | Tel.: (93) 99160-6045 | E-mail: isaias. pereira@ifpa.edu.br

\section{Revista Ambiente Construído}

Associação Nacional de Tecnologia do Ambiente Construído

Av. Osvaldo Aranha, 99 - 3o andar, Centro

Porto Alegre - RS - Brasil

$$
\text { CEP } 90035-190
$$

Telefone: +55 (51) 3308-4084

Fax: +55 (51) 3308-4054

www. seer. ufrgs. br/ ambienteconstruido

E-mail: ambienteconstruido@ufrgs.br 